Research Article

\title{
Design and Analysis of a Stand-Alone PV System for a Rural House in Pakistan
}

\author{
Amjad Iqbal (iD) and M. Tariq Iqbal \\ ECE, Faculty of Engineering and Applied Sciences, Memorial University of Newfoundland, Canada \\ Correspondence should be addressed to M. Tariq Iqbal; tariq@mun.ca
}

Received 29 August 2018; Revised 8 February 2019; Accepted 7 March 2019; Published 23 April 2019

Guest Editor: Mattia De Rosa

Copyright (c) 2019 Amjad Iqbal and M. Tariq Iqbal. This is an open access article distributed under the Creative Commons Attribution License, which permits unrestricted use, distribution, and reproduction in any medium, provided the original work is properly cited.

In this paper, thermal modeling of a typical rural house in Pakistan has been done using BEopt, to determine the hourly load profile. Using the load data, the design of a stand-alone PV system has been completed using HOMER Pro. The designed system consists of a $5.8 \mathrm{~kW}$ PV with eight batteries of $12 \mathrm{~V}, 255 \mathrm{Ah}$, and a $1.4 \mathrm{~kW}$ inverter. The system analyses show that such system can support mainly lighting and appliance load in a rural house. The dynamic model of the designed system has been simulated in MATLAB-Simulink. Perturbation and observation-based algorithm has been used for maximum power extraction from PV. Simulation results indicate that the system can provide a stable voltage and frequency for the domestic load. The method and analysis presented here can be used for the PV system design for other parts of the world.

\section{Introduction}

In this case study, a rural house in Pakistan has been considered for the load profile, PV sizing, and system design. It was selected because most of the remote communities of underdeveloped countries like Pakistan have high solar resource but are isolated from the main grid, and they face long hours of load shedding. The system analysis, sizing, and current per kilowatt hour cost encourage renewable energy and PV system in other parts of the world specifically in the countries of South Africa and South Asia which are rich in solar resource and have the insufficient electric supply. Therefore, this study will help in implementing small PV systems to meet the domestic load demand of the people living in the solar irradiance-rich areas of the world.

The efficiency and output power of PV depend upon the solar irradiance, location, face angle of the PV panel, type of PV (monocrystalline, polycrystalline, microamorphous silicon, and amorphous silicon), and the efficiency of the components, but the available solar irradiance and location play a significant role [1]. Another study [2] showed that the hybrid system of PV and diesel would be viable than a stand-alone PV system. The latest research has led to a significant improvement in the efficiency of the PV system to harness the clean energy [3]. Due to this, the stand-alone PV systems are becoming more ubiquitous for the electrification of off-grid communities and other projects like the water pumping system [4-6], and in this growing trend, this study will be helpful for small PV system designing and sizing.

Pakistan is a developing country, and it is facing a power crisis for more than twenty years. The gap in power generation $(18,000 \mathrm{MW})$ and demand $(25,000 \mathrm{MW})$ is continuously increasing, because load shedding hours in the rural areas are increasing every year and now have reached up to $6 \mathrm{~h}$ in winter and $10 \mathrm{~h}$ in summer [7-10]. To meet the urban and industrial sector power demand, the power of the rural area is cut down resulting more suffering of rural people than urban people. More than $50 \%$ of the population of Pakistan is living in rural areas, and daily power outage is one of the main reasons for the low GDP [11]. The sufferings of the rural people and some assumptions made in the sizing of such system [12] are the driving forces for this research work.

If an alternate system is designed for the rural people, it would not only reduce their worries but will also make improvements in the country's GDP. Fortunately, Pakistan is rich in solar energy potential, and according to Jamal and 


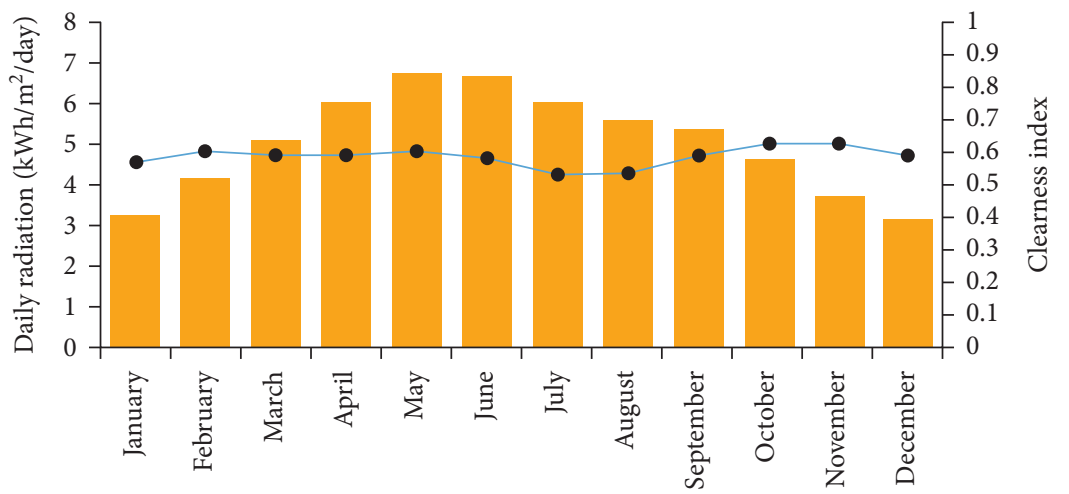

Figure 1: Solar energy potential at the selected location.

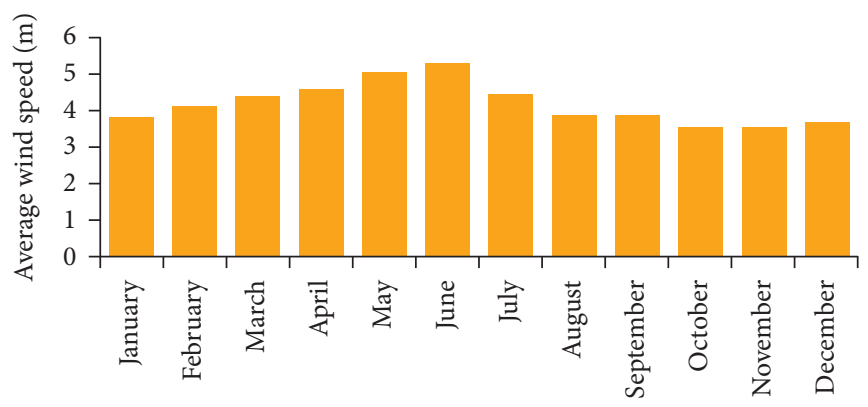

Figure 2: Wind speed data for the selected location $(50 \mathrm{~m})$.

TABLE 1: Load estimate of a typical rural house in Pakistan.

\begin{tabular}{|c|c|c|c|c|c|}
\hline Load & Lights & Fans & Refrigerator & $\mathrm{TV}\left(17^{\prime \prime}\right)$ & \\
\hline Power rating & $25 \mathrm{~W}$ & $75 \mathrm{~W}$ & $200 \mathrm{~W}$ & $150 \mathrm{~W}$ & Miscellaneous load \\
\hline \# of items & 4 & 3 & 1 & 1 & \\
\hline Total power & $100 \mathrm{~W}$ & $225 \mathrm{~W}$ & $200 \mathrm{~W}$ & $150 \mathrm{~W}$ & $100 \mathrm{~W}$ \\
\hline
\end{tabular}

Hohmeyer and Stackhouse et al. [13, 14], the annual solar irradiance ranges from 4.0 to $5.28 \mathrm{kWh} / \mathrm{m}^{2} /$ day. Figure 1 shows the average monthly sunshine of 250 ?h for the chosen site. Although, many papers like [13, 15-17] have been written on this topic, most of them address generic issues of the PV system, and even in [12], an attempt has been made to size and propose a PV system for a typical house and a load of a house has been considered to be $5 \mathrm{kWh} /$ day ( $1800 \mathrm{kWh} /$ year). Further, the proposed system is undersized, and idealistic conditions have been assumed like daily solar irradiance would be greater than $5 \mathrm{kWh} / \mathrm{m}^{2} /$ day and intermittence of weather conditions and bad weather backup has not been taken into considerations. We present complete thermal modeling of a typical house done in BEopt to observe the hourly load profile for one year, and according to that, the system sizing has been completed. Using HOMER Pro, an optimized and low-cost system has been selected which gives energy at the rate of $\$ 0.19 / \mathrm{kWh}$ and the system design has been explained in the coming sections. Simulations of a stand-alone PV system have been completed in Simulink. In the proposed system's simulations, a perturbation and observation-based maximum power point tracking (MPPT) algorithm has been implemented, and the battery bank protection against under/overvoltage has been carried out. MPPT is the operating state of the PV at which it delivers maximum power to a resistive load [18]. Before opting the PV system, the study of other available energy resources was also done. Annual wind speed data for the selected site has been shown in Figure 2. The average annual wind speed is not more than $4.15 \mathrm{~m}^{-1}$ [14], because wind energy use was eliminated. The rural areas in Pakistan are not rich in geothermal energy source because geotemperature varies by only $3-3.5^{\circ} \mathrm{C}$ for the depth of $100 \mathrm{~m}$ [19-21]. Similarly, ocean energy could not be considered because more than $50 \%$ of the population of Pakistan lives in the Punjab Province which is more than $500 \mathrm{~km}$ away from the ocean. A brief analysis of available renewable energy resources for a typical house and hourly energy consumption for one year has been estimated in Section 2. Section 3 explains the HOMER Pro-based system sizing for the house including the size of the proposed PV system considering 18\% efficiency. A single inverter and a battery bank which can provide backup for more than two days in abnormal weather conditions have been selected. Simulink-based simulations have been explained in Section 4. The last section gives the conclusion and analysis of the proposed system. 


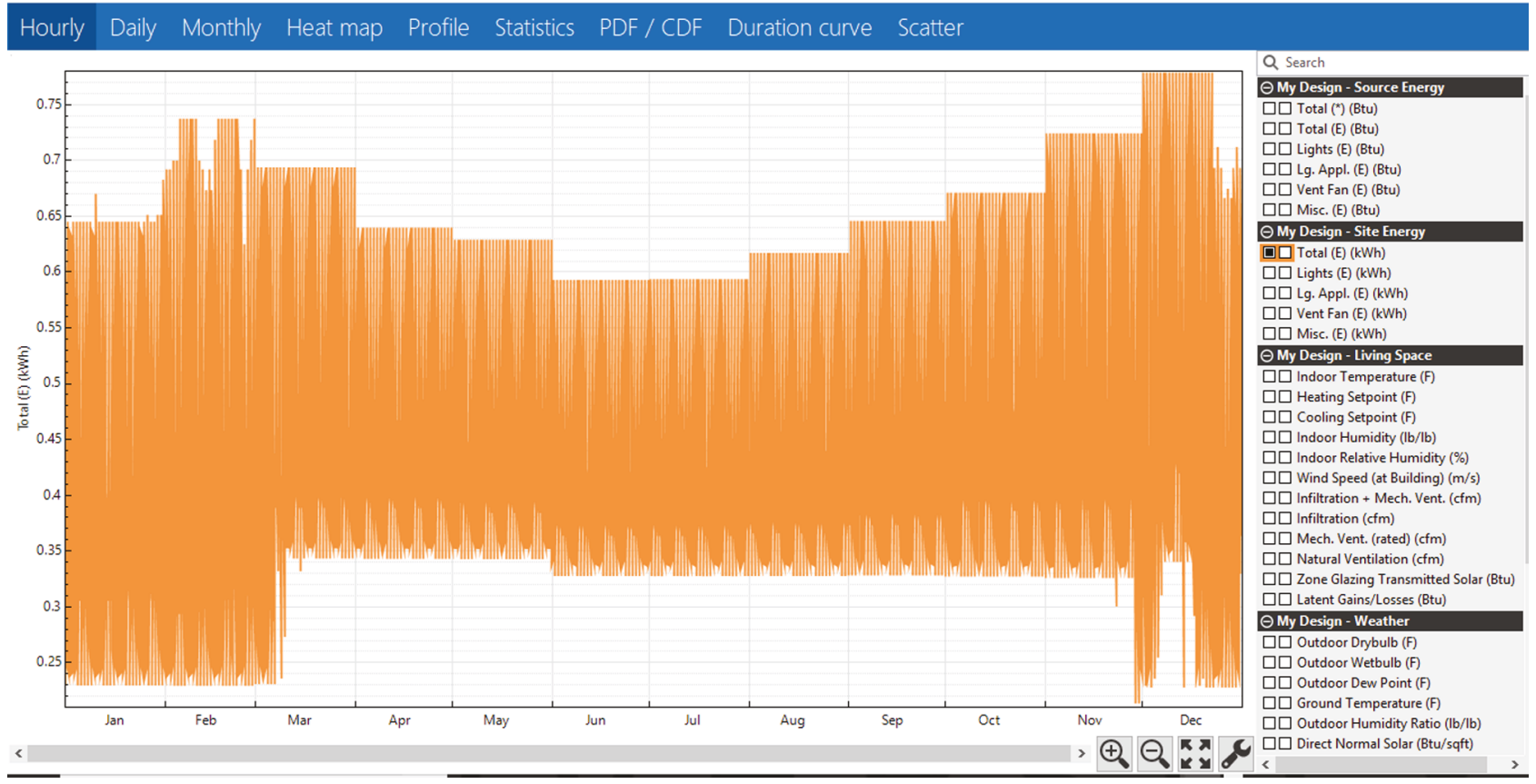

(a)

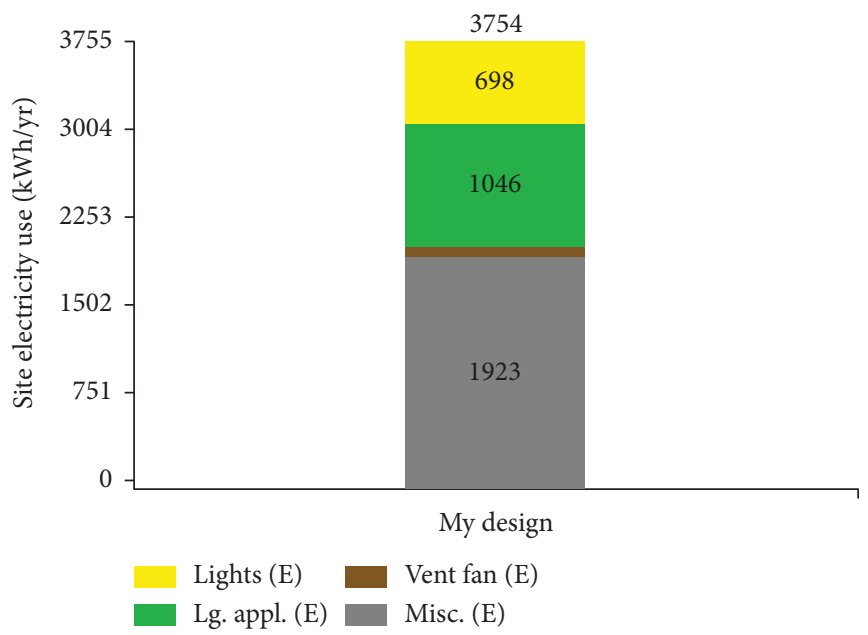

(b)

Figure 3: (a) Hourly load flow data of the house for a typical year. (b) Annual energy consumption of the house by different types of load (lights, large appliances, ventilation fans, and miscellaneous load).

\section{Estimation of the Hourly Load and Annual Energy Consumption of the House}

The selected house is in a remote community of Punjab Province and in the outskirts of district Faisalabad with the coordinates of $31^{\circ} 13^{\prime} \mathrm{N}$ and $73^{\circ} 24^{\prime} \mathrm{E}$. The thermal modeling has been completed by estimating the residential load; the results of annual energy consumption from BEopt were compared with the utility bill, and a minor variation of less than $4 \%$ was observed.

In the rural areas, people do not use electric heaters or air conditioner for heating/cooling purposes and for cooking they use petroleum gas or wood. The typical load is very small, and an approximated load of a typical house is 7-
$9 \mathrm{kWh}$ /day according to the BEopt results. Here, in system sizing backup, storage has been assumed to be $10 \mathrm{kWh} /$ day. Load of Table 1 was entered in BEopt, which was collected by counting the number of active appliances and their nameplate power consumption. The hourly load profile for a year was generated and has been shown in Figure 3(a) which shows that the energy consumption is relatively higher in the months of February, November, and December due to longer nights. Figure 3(b) shows the total kWh consumption round the year by different load types (lights, large appliances, ventilation fans, and other miscellaneous appliances). Miscellaneous load seems too high compared to others because it accommodates all different types of load other than the list presented in Table 1. 


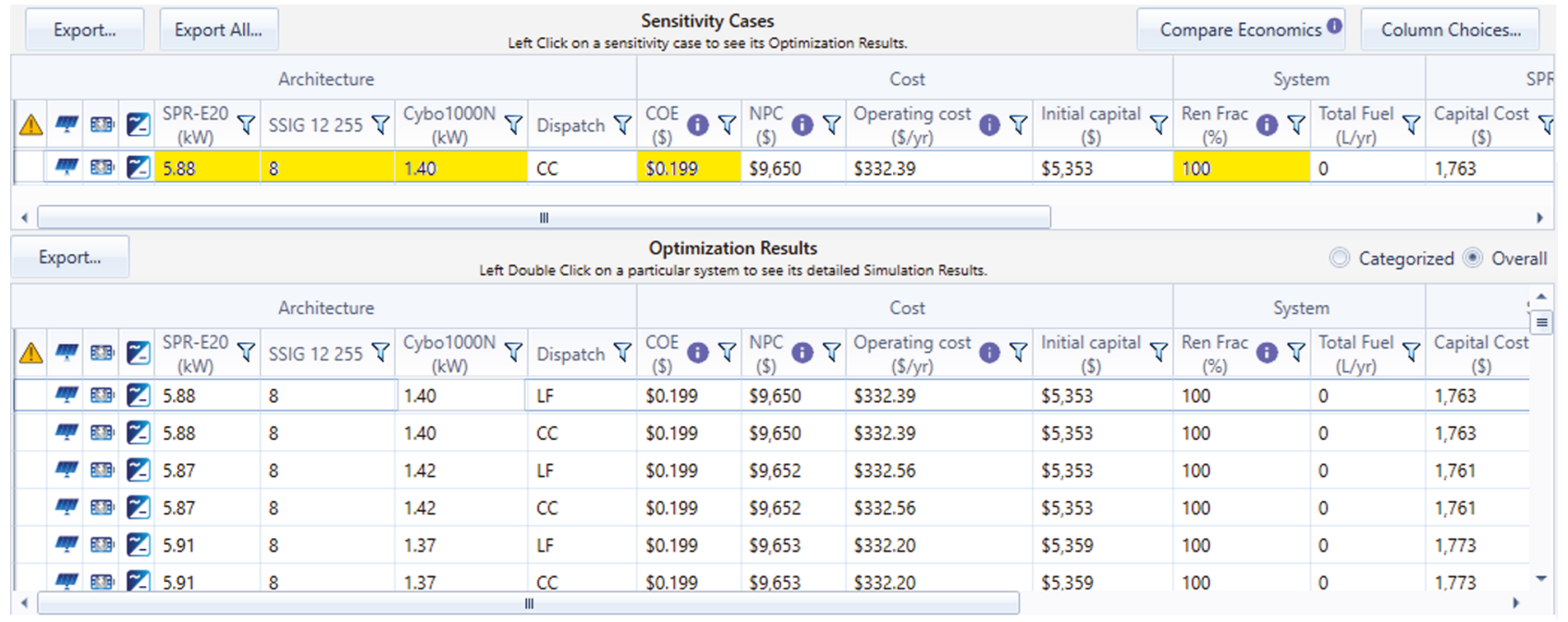

FIgURE 4: HOMER sizing and optimization results.
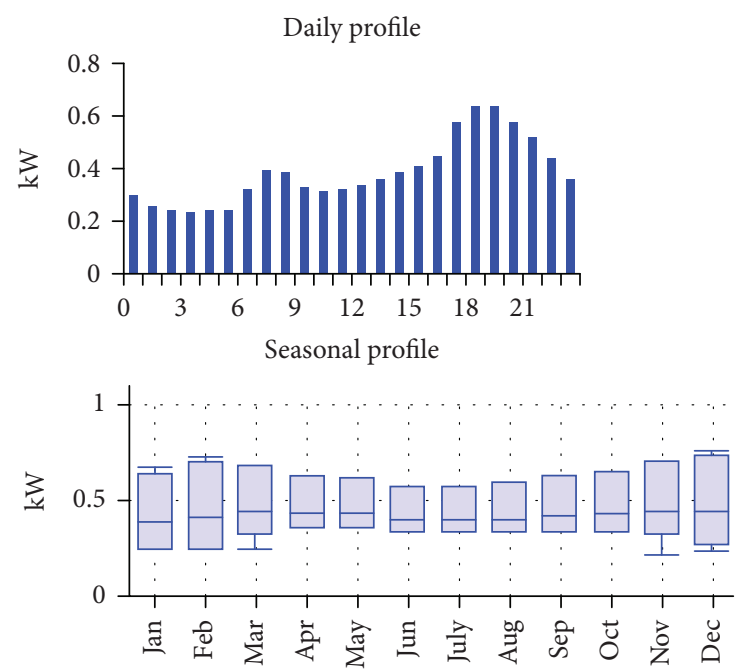

\begin{tabular}{lll}
\multicolumn{1}{c}{ Metric } & Baseline & Scaled \\
\hline Average $(\mathrm{kWh} / \mathrm{d})$ & 10.28 & 10.28 \\
Average $(\mathrm{kW})$ & .43 & .43 \\
Peak $(\mathrm{kW})$ & .77 & .77 \\
Load factor & .56 & .56
\end{tabular}

Load type: (-) AC DC

(a)
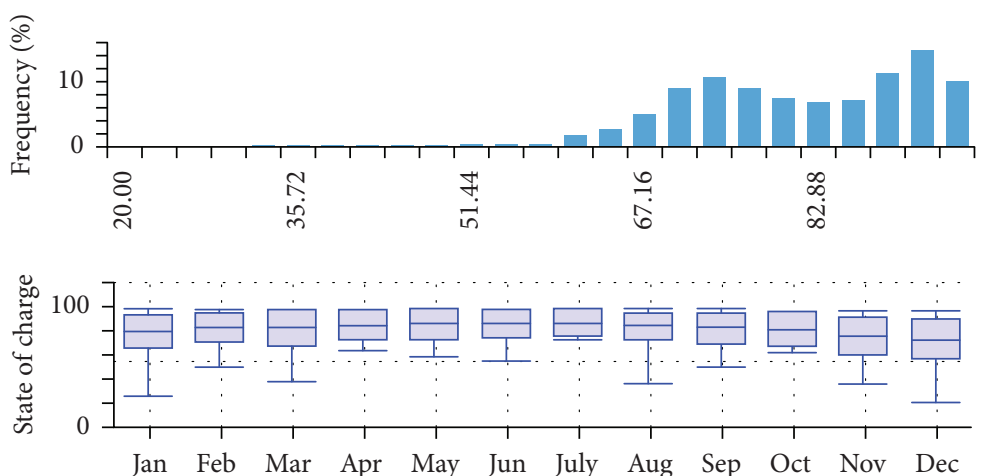

Figure 5: (a) Hourly load profile for a typical day and average demand of each month. (b) Battery bank discharge frequency and the depth of discharge.

TABle 2: Project estimated costs [24].

\begin{tabular}{lccc}
\hline Component & PV & Converter & Battery \\
\hline Rating of each component & $327 \mathrm{~W}$ & $1.4 \mathrm{~kW}$ & SSIG 12 V, 255 Ah \\
Required \# of components & 18 & 1 & 8 \\
Final rating & $5.886 \mathrm{~kW}$ & $1.4 \mathrm{~kW}$ & $48 \mathrm{~V}, 510 \mathrm{Ah}$ \\
Cost/unit & $\$ 173$ & $\$ 180$ & $\$ 426$ \\
Total cost & $\$ 3114$ & $\$ 180$ & $\$ 3408$ \\
\hline
\end{tabular}




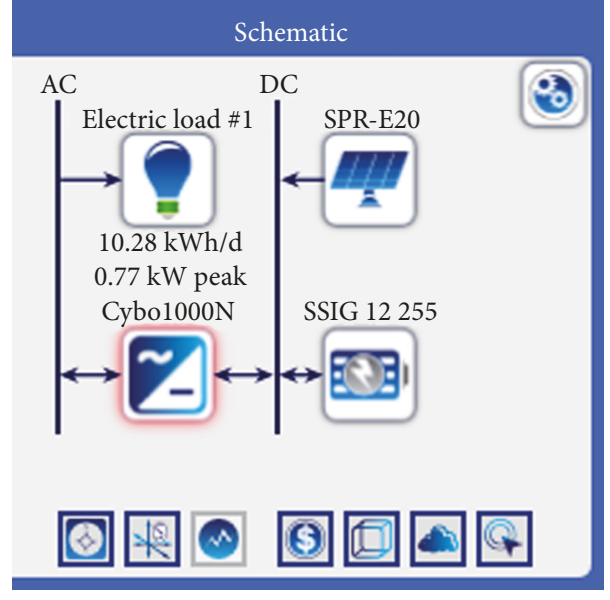

(a)

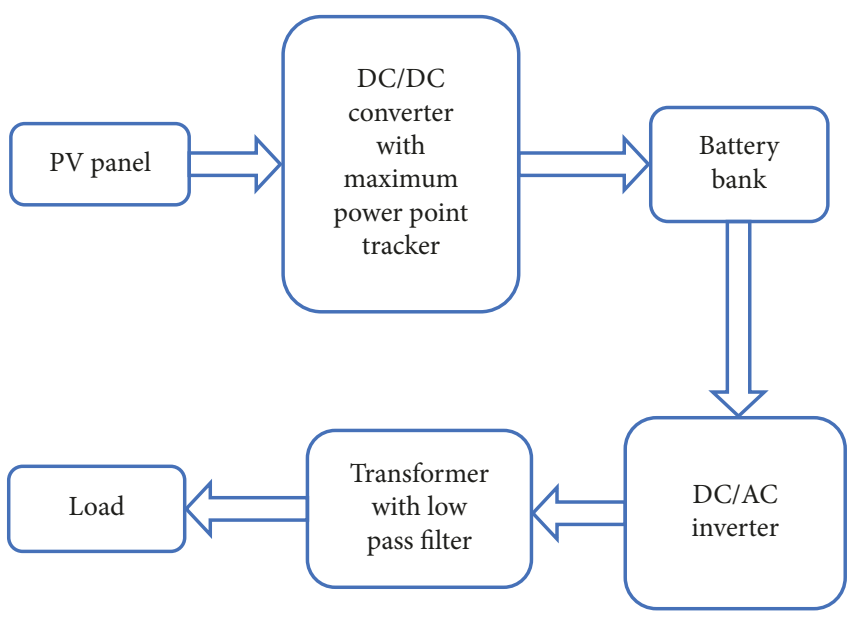

(b)

Figure 6: (a) System structure with integrated subblocks. (b) Flow chart of the system structure with subblocks followed in Simulink simulations.

\section{System Sizing and Optimization}

The desired system sizing was completed in HOMER Pro; the data for solar irradiance was downloaded from [22], and HOMER results have been shown in Figure 4. In results, more than 3000 different combinations consisting of a different number of PV panels and battery banks were calculated in HOMER and, finally, the chosen system was found the most economical considering the factors such as initial capital cost, cost $/ \mathrm{kWh}$, net present cost, unmet load, excess electricity generation, and the efficiency of the system. According to the optimized results, the PV panels of SunPower $5.88 \mathrm{~kW}$, 8 batteries of SSIG $12 \mathrm{~V}, 255 \mathrm{Ah}$ (two strings of $48 \mathrm{~V}$ ), and a converter of $1.4 \mathrm{~kW}$ will be enough to meet the load. For PV, SunPower polycrystalline has been selected due to the economical reasons despite its relatively less efficiency (18\%) as compared to the silicon monocrystalline PV panels (20\%) [23]. The above proposed system gives the power backup for $47 \mathrm{~h}$ for bad weather conditions as well and has minimum excess electricity. The power inverter is $1.4 \mathrm{~kW}$, and it has been sized based upon the peak demand of AC load which is not more than $800 \mathrm{~W}$ during peak time. The required PV panel was sized considering the factors of load demand, required power backup, irradiance, etc. Therefore, there is a difference between PV panel size $(5.8 \mathrm{~kW})$ and the converter rating $(1.4 \mathrm{~kW})$. When the PV output is sufficient to meet the load demand, the battery bank will be in floating state and will only be discharged during night time or when the PV output becomes insufficient to meet load demand. Further, the average daily energy consumption of the house is $10.3 \mathrm{kWh}$; therefore, the proposed battery bank size determined in HOMER size optimization will be sufficient to give backup of $47 \mathrm{~h}$ for bad weather conditions. In actual system sizing, a safety factor of 1.3 times has also been included to protect against overloading or withstand the surges and the efficiency of the PV system has been taken $18 \%$ according to the nameplate of SunPower.

The load profile and the battery state of charge have been shown in Figures 5(a) and 5(b), respectively. Figure 5(a) shows the 24-hour load profile with peak hours of early morning and evening as observed in our real system, and the average daily demand is not more than $10.3 \mathrm{kWh}$. Figure 5(b) shows the storage state of charge and the percentage of discharge, and depth of discharge is never worse than $25 \%$. Table 2 shows the information about the rating and cost of the system components. Most of the data about components' cost were collected from [24]. It includes $70 \%$ of replacement cost, and it can be seen that the overall project does not cost more than $\$ 9650$.

The site does not have sufficient sources of wind and geothermal energy as indicated in the literature review; therefore, those sources have not been included in HOMER sizing and optimizations. The chosen site has no obstacles or trees to cause the shadow on the PV system; therefore, shadow and its impact have been ignored.

\section{Proposed System Simulations in Simulink}

The system block diagram has been shown in Figure 6 . Figure 6(a) shows the block diagram of the system in which the solar panel with the maximum power point tracker (MPPT) is connected with the DC bus. The block of the battery bank which also has the charge controller and under/overvoltage protection is connected with the same DC bus. The third block in this figure is the Cybo1000N converter which not only converts DC into AC but also ensures the power quality (reduce the harmonics) and links the DC and AC buses. The simulations of the proposed system have been completed in Simulink following the block diagram shown in Figure 6(b) which is the extension of the blocks shown in Figure 6(a).

In the Simulink simulations, the PV system output is fed to the block of the DC/DC converter with a controller. The algorithm of the maximum power point tracker (MPPT) has been implemented in the same block to control the duty cycle of the converter. It maintains the output DC voltage equal to $48 \mathrm{~V}$ and feeds to the battery bank. Under normal operating conditions (when the PV output is enough to meet 


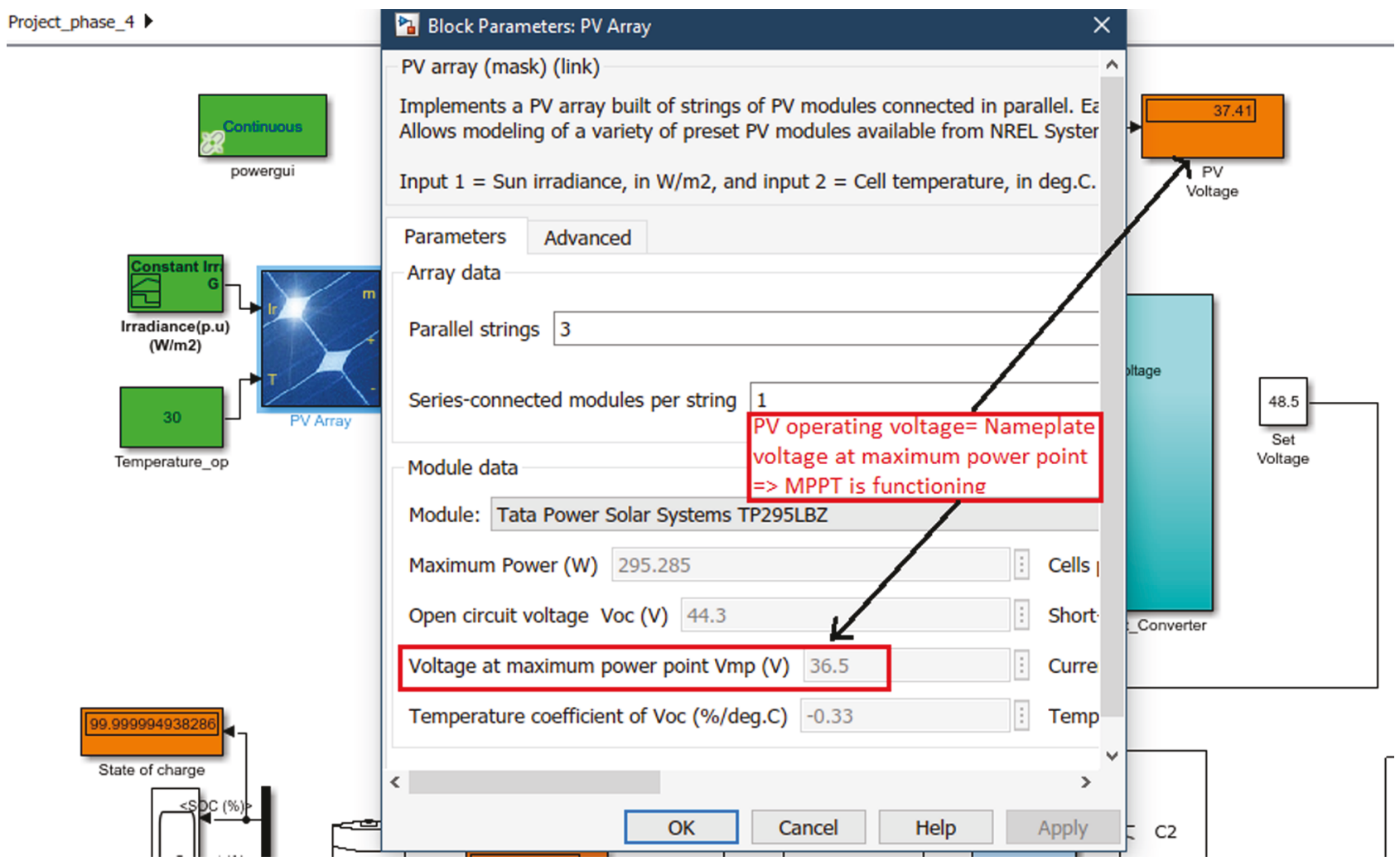

(a)

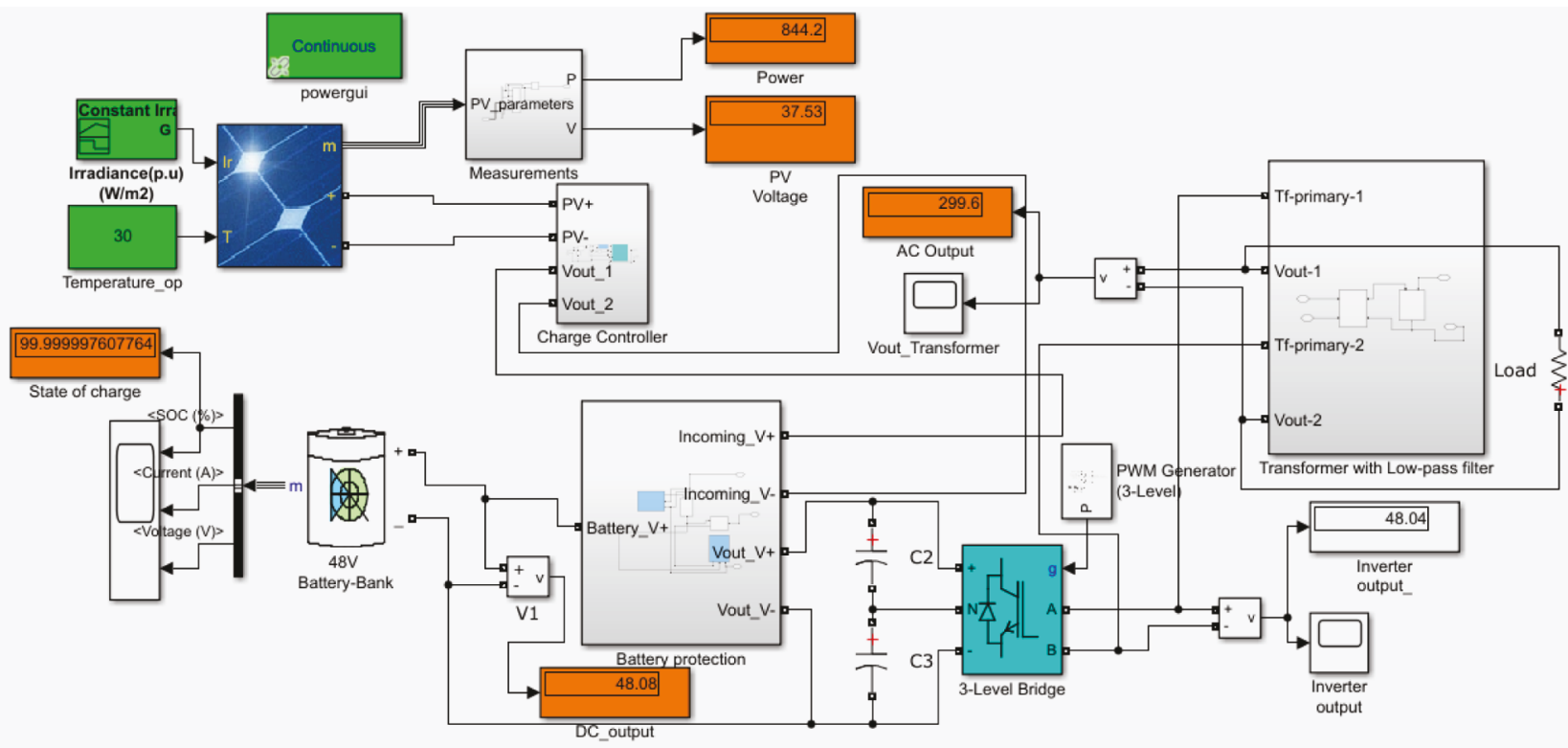

(b)

Figure 7: (a) Output voltage of PV when the system is operating at maximum power point (MPP) under MPPT. (b) Simulink simulations for the complete system.

load demand), the battery bank will be in a floating state. Therefore, its state of charge shown in Figure 7 shows that it fully charged. Single-phase six-step inverter which operates with a switching frequency of $5 \mathrm{kHz}$ is connected with the battery bank. Its output is a six-step AC waveform with $50 \mathrm{~Hz}$ frequency which is the standard power system frequency in Pakistan. The voltage level of the six-step AC form is boosted to $212 \mathrm{~V}$ RMS ( $300 \mathrm{~V}$ peak) by a single-phase transformer which also has a filter on secondary winding to reduce the harmonics.

To track the maximum power point for PV, perturbation and observation-based algorithm has been implemented. It was opted out of many other algorithms because of its simplicity and quick response and is free 


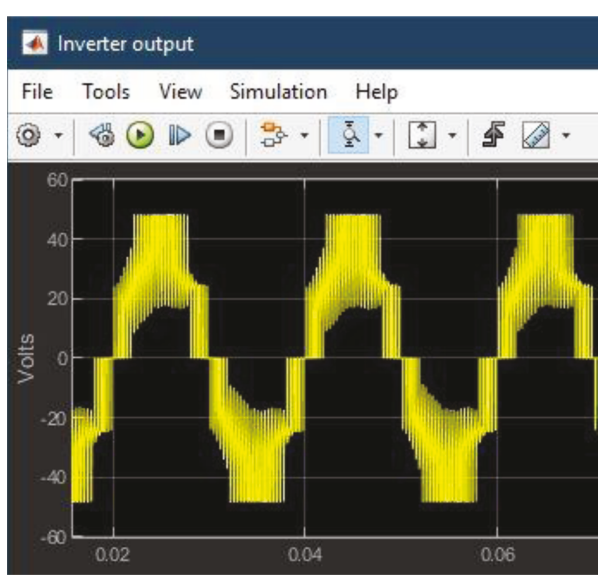

(a)

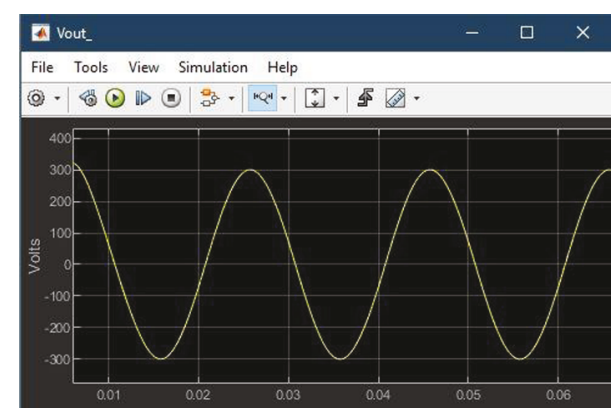

(b)

FIgURE 8: (a) Output of the 6-step inverter (low-voltage side). (b) Final output of $50 \mathrm{~Hz}, 212 \mathrm{~V}$ RMS for the AC load (high-voltage side).

from derivatives and integrals like other algorithms. In Simulink, the battery protection unit protects the battery from deep discharging and also protects from overvoltage for any abnormal condition. The battery protection units for the battery bank and system are based upon the comparison of the output voltage and the reference Zener voltage, and based upon that, a decision is made whether to keep the system connected or turned off. The design calculations for the buck-boost converter were completed using equation (1) [25], and the filter design was completed following [26]. In the following equations, $D$ is for duty cycle and $f$ is for the switching frequency:

$$
\begin{gathered}
L \geq \frac{(1-D)^{2}}{2 f} R, \\
C=(2 \pi f)^{2} L .
\end{gathered}
$$

The complete Simulink diagram has been shown in Figures $7(a)$ and 7(b). Figure 7(a) shows the output voltage of PV when MPPT is controlling its operating point. In Figure $7(\mathrm{a})$, the voltage is $37.5 \mathrm{~V}$ and with time MPPT fixes the output exactly equal to the nameplate value of the PV to get maximum power. Figure 7(b) shows the complete Simulink diagram of the system which gives the desired output and corroborates the system validations. The simulation results have been shown in Figure 8, where Figure 8(a) shows the output of a six-step inverter and Figure 8(b) shows the final output of the system which is $212 \mathrm{~V}$ RMS $(600 \mathrm{~V}$ peak-to-peak voltage) with the standard frequency of $50 \mathrm{~Hz}$. This simulation identifies all electrical parts required for the system and can be used to study the impact of changing inputs on the output voltage.

\section{Conclusion}

For a typical house of the rural area in Pakistan, the complete thermal modeling, sizing, and optimization of a stand-alone PV system with detailed cost calculations have been presented in this paper. The designed system consists of $5.8 \mathrm{~kW} \mathrm{PV}$, eight batteries of $12 \mathrm{~V}$ and $255 \mathrm{Ah}$, and a
$1.4 \mathrm{~kW}$ inverter, and overall, it costs $\$ 9650$ and produces electricity at $\$ 0.199 / \mathrm{kWh}$. This research presents a detailed procedure to design a PV system for remote locations where grid supply is not possible or economically viable. Following this method, one can estimate the load, size a system, simulate the system, and determine the expected performance. Therefore, this study seems potentially helpful in designing a stand-alone PV system.

\section{Future Work}

It could be seen that the battery bank requires a significant capital cost which overall affects the system economical viability. In the future, a large scale implementation of the PV system study could be done to explore the implementation of other combinations for energy storage systems along with the battery bank, e.g., compressed air, hydrogen gas, flywheel, pumped hydro, and other options like these. A hybrid and cheaper energy storage system will prove helpful in harnessing clean and cheap energy.

\section{Data Availability}

The data used to support the findings of this study are available from the corresponding author upon request.

\section{Conflicts of Interest}

The authors of this work declare that all used software and devices were selected on professional basis. Furthermore, the authors certify that there is no actual or potential conflict of interest in relation to this article.

\section{Acknowledgments}

This research was funded by the Natural Sciences and Engineering Research Council (NSERC) of Canada. The authors would like to acknowledge the financial support of the NSERC and the technical support of friends, family, and the Memorial University of Newfoundland. 


\section{References}

[1] C. R. Charan, A. J. Laxmi, and P. Sangeetha, "Optimized energy efficient solution with stand alone PV system," MATTER: International Journal of Science and Technology, vol. 3, no. 1, pp. 16-27, 2017.

[2] H. Rezzouk and A. Mellit, "Feasibility study and sensitivity analysis of a stand-alone photovoltaic-diesel-battery hybrid energy system in the north of Algeria," Renewable and Sustainable Energy Reviews, vol. 43, pp. 1134-1150, 2015.

[3] Global CCS Institute, "Renewable generation scenarios from 2020," https://hub.globalccsinstitute.com/publications/ renewable-energy-review/4-renewable-generation-scenarios2020.

[4] B. Bogno, J. P. Sawicki, P. Petit et al., " $230 \mathrm{~V}_{\mathrm{DC}}$ elementary block in off-grid PV systems," Sustainable Energy Technologies and Assessments, vol. 29, pp. 1-11, 2018.

[5] K. Rahra, D. Rekioua, T. Rekioua, and S. Bacha, "Photovoltaic pumping system in Bejaia climate with battery storage," International Journal of Hydrogen Energy, vol. 40, no. 39, pp. 1366513675, 2015.

[6] A. Mohammedi, D. Rekioua, and N. Mezzai, "Experimental study of a PV water pumping system," Journal of Electrical Systems, vol. 9, no. 2, pp. 212-222, 2013.

[7] K. Kiani, Loadshedding Rears Its Head as Fuel Stocks Dip, DAWN, 2018, https://www.dawn.com/news/1405137.

[8] International Renewable Energy Agency, Renewable Readiness Assessment Pakistan, IRENA, Abu Dhabi, 2018.

[9] The DAWN, "Load-shedding despite megawatts7, July 2018, https://www.dawn.com/news/1405341.

[10] National Transmission and Despatch Company, Power System Statistics 2014-2015, NTDC, Lahore, 2015.

[11] G. Saghir and S. Malik, "Estimating monetary policy reaction function of the State Bank of Pakistan," August 2018, http:// pu.edu.pk/images/journal/pesr/PDF-FILES/7-v55_1_17.pdf.

[12] M. Ali, A. Yousaf, and F. G. Seharan, "Feasibility evaluation of stand-alone photovoltaic systems for residential loads," in 2018 9th International Renewable Energy Congress (IREC), pp. 1-4, Hammamet, Tunisia, March 2018.

[13] N. Jamal and O. Hohmeyer, "Solar resources' potential role in the development of renewable based electric power system by 2050: the case of Pakistan prospects of solar in Pakistan," in 2014 International Conference on Energy Systems and Policies (ICESP), pp. 1-7, Islamabad, Pakistan, November 2014.

[14] P. W. Stackhouse, D. Westberg, J. M. Hoell, W. S. Chandler, and T. Zhang, "Atmospheric Science Data Center," Surface Meteorology and Solar Energy, vol. 3.1.2, pp. 9-24, 2013, Release 6.0 Methodology.

[15] R. S. Farswan, H. Khan, and B. G. Fernandes, "A low cost reliable stand-alone photo-voltaic system," in 2014 IEEE International Conference on Power Electronics, Drives and Energy Systems (PEDES), Mumbai, India, December 2014.

[16] M. F. Aziz and N. Abdulaziz, "Prospects and challenges of renewable energy in Pakistan," in 2010 IEEE International Energy Conference, pp. 161-165, Manama, Bahrain, December 2010.

[17] G. N. Prodromidis and F. A. Coutelieris, "A comparative feasibility study of stand-alone and grid connected RES-based systems in several Greek Islands," Renewable Energy, vol. 36, no. 7, pp. 1957-1963, 2011.
[18] A. Daniela, P. Ejnar, and W. Henrik, "Models for a stand-alone PV system," Forskningscenter Risoe. Risoe-R, vol. 1219, no. 1219, 2001.

[19] U. Younas, B. Khan, S. M. Ali et al., "Pakistan geothermal renewable energy potential for electric power generation: a survey," Renewable and Sustainable Energy Reviews, vol. 63, pp. 398-413, 2016.

[20] N. Alam Zaigham, Z. Alam Nayyar, and N. Hisamuddin, "Review of geothermal energy resources in Pakistan," Renewable and Sustainable Energy Reviews, vol. 13, no. 1, pp. 223232, 2009.

[21] I. A. Gondal, S. A. Masood, and M. Amjad, "Review of geothermal energy development efforts in Pakistan and way forward," Renewable and Sustainable Energy Reviews, vol. 71, pp. 687696, 2017.

[22] R. Affolter, Pakistan - Solar Radiation Measurement Data (2014 - 2017), World Bank Group, Islamabad, 2018.

[23] S. Das and A. K. Akella, "Power flow control of PV-windbattery hybrid renewable energy systems for stand-alone application," International Journal of Renewable Energy Research, vol. 8 , no. $1,2018$.

[24] https://www.solaris-shop.com/trojan-signature-ssig-12-255flooded-12v-229ah-battery/.

[25] G. Stahl, M. Rodriguez, and D. Maksimovic, "A high-efficiency bidirectional buck-boost DC-DC converter," in 2012 TwentySeventh Annual IEEE Applied Power Electronics Conference and Exposition (APEC), pp. 1362-1367, Orlando, FL, USA, February 2012.

[26] R. W. Erickson and D. Maksimovic, Fundamentals of Power Electronics, Springer US, New York, NY, USA, 2nd edition, 2001. 

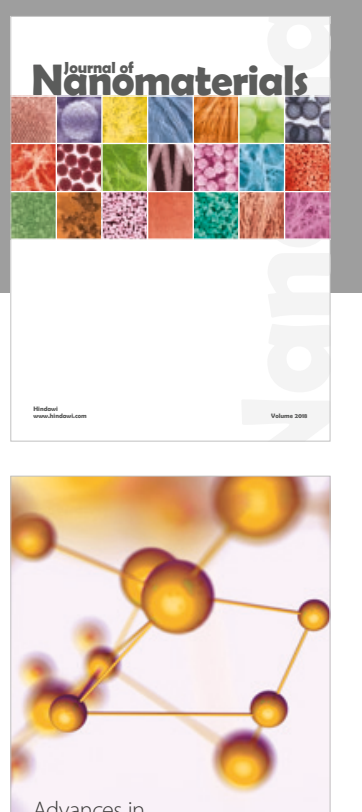

Physical Chemistry
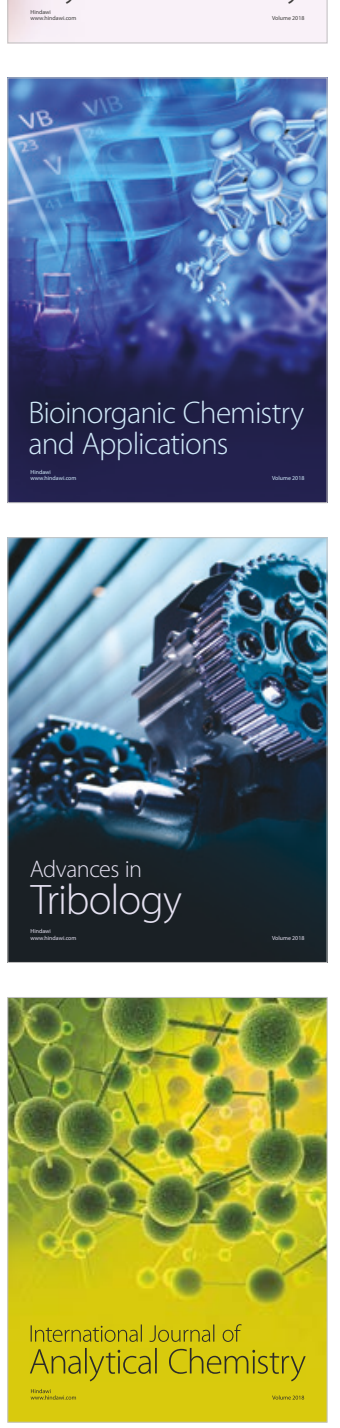

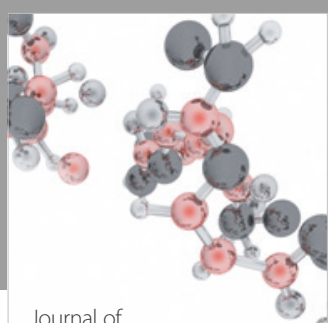

Analytical Methods

in Chemistry

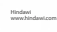

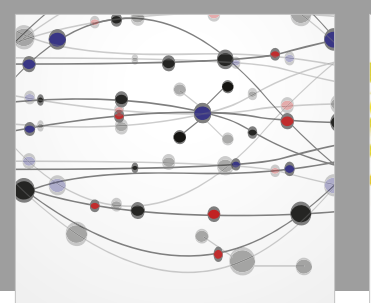

The Scientific World Journal

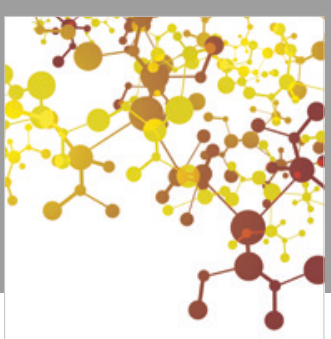

Journal of

Applied Chemistry
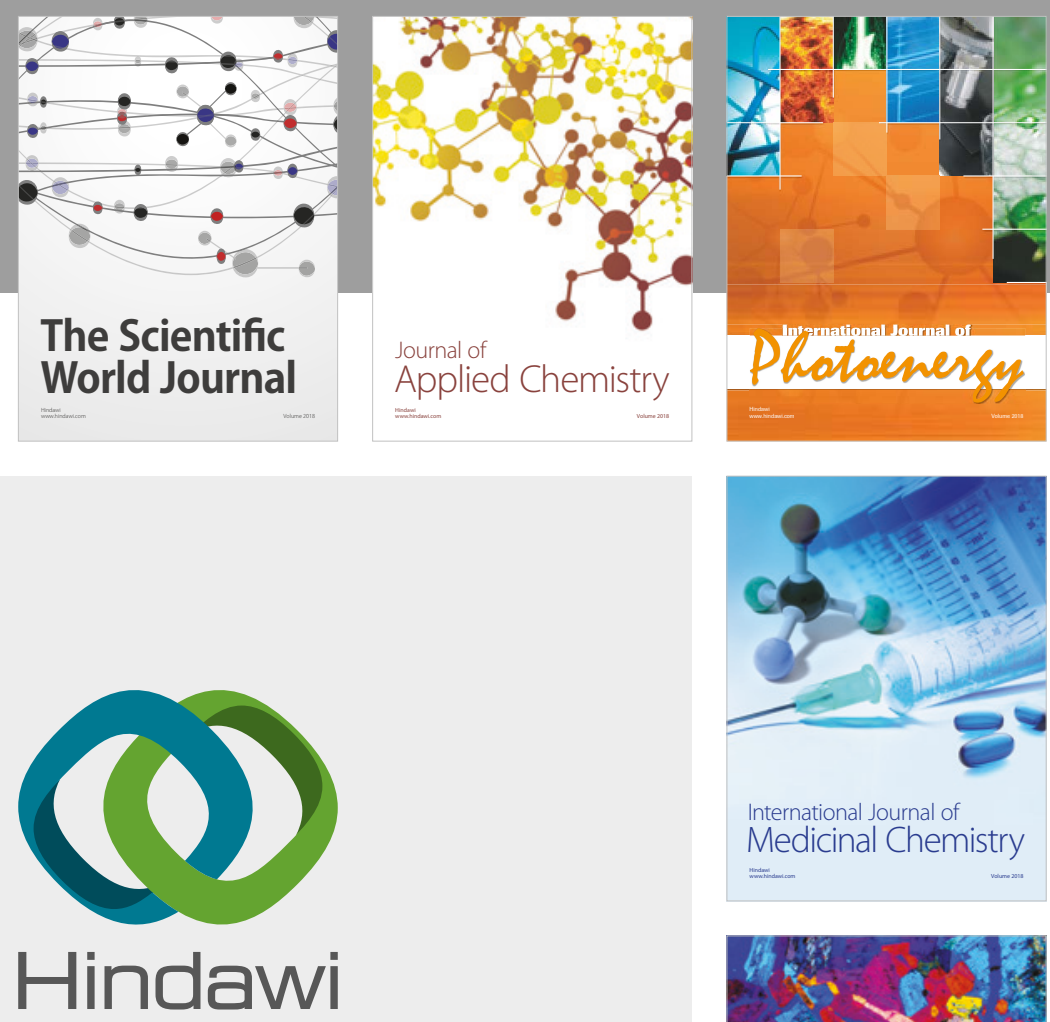

Submit your manuscripts at

www.hindawi.com
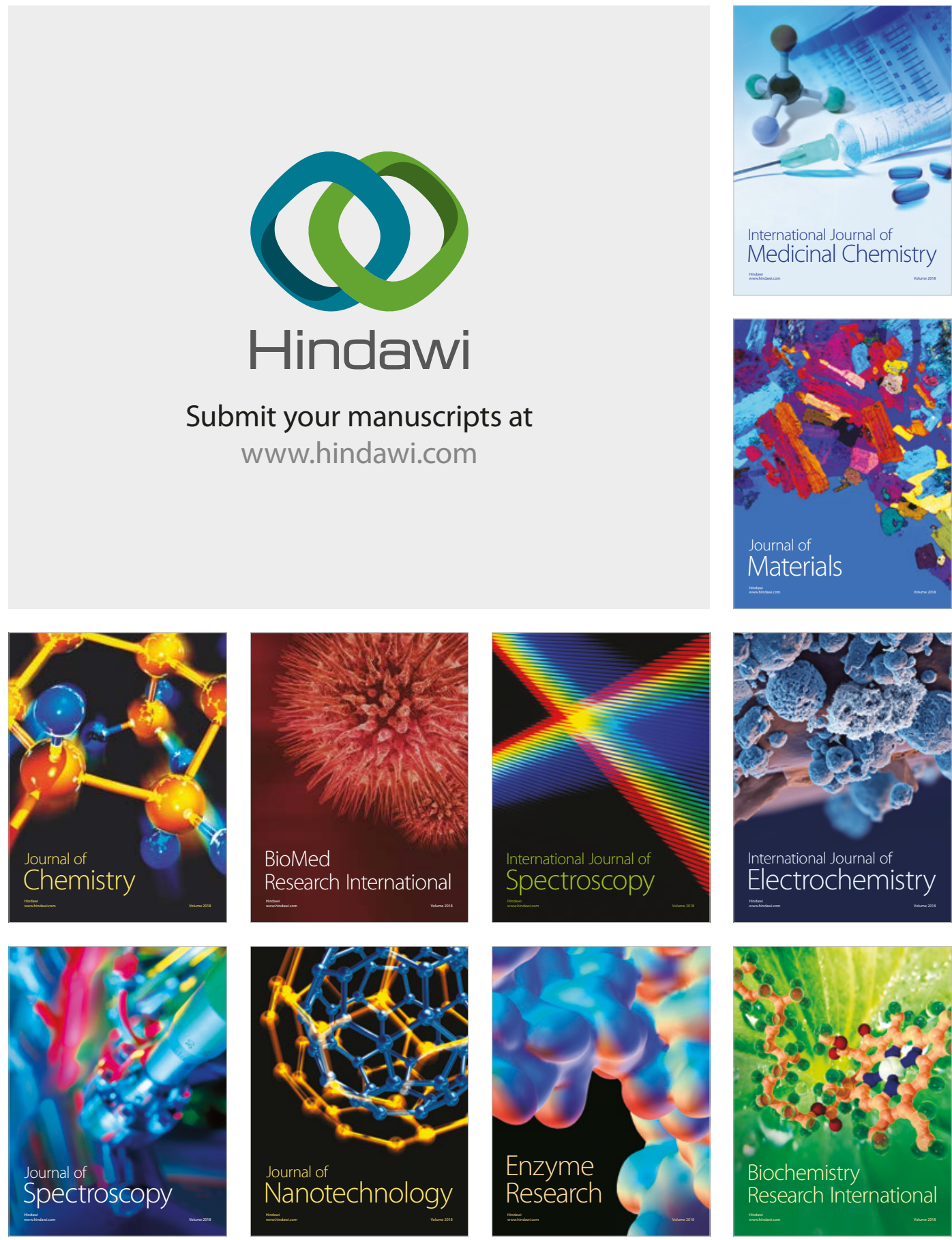
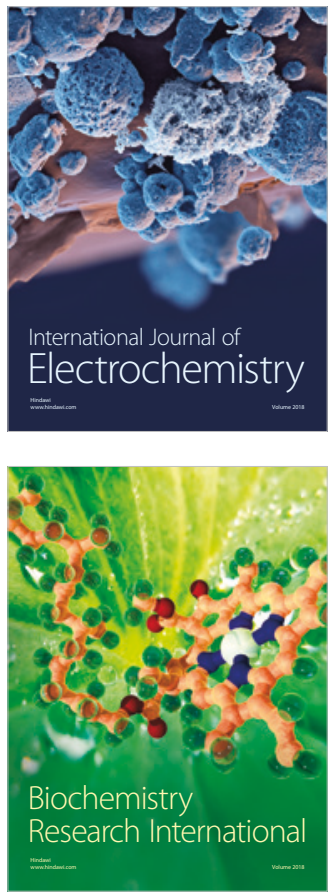